\title{
Using the Circuit Training Method to Promote the Physical Fitness Components of the Hashemite University Students
}

\author{
Mahmoud Al-Haliq \\ Coaching and Sport Management Department, The Hashemite University, Zarqa, Jordan \\ Email: amana752001@yahoo.com, m alhaliq@yahoo.com
}

Received 12 June 2015; accepted 18 July 2015; published 21 July 2015

Copyright (C) 2015 by author and Scientific Research Publishing Inc.

This work is licensed under the Creative Commons Attribution International License (CC BY).

http://creativecommons.org/licenses/by/4.0/

(c) (i) 0 pen Access

\begin{abstract}
This study aimed at identifying the effect of using the circuit training method on promoting the physical fitness components among the Hashemite University freshmen students who were enrolled in the Physical Fitness Course. The experimental design was utilized. The study sample consisting of (15) male and (15) female students was enlisted in the Physical Fitness Course in the first semester of the university academic year 2014/2015. The study sample was chosen by the intentional method. The researcher determined the tests that measured the physical fitness components based on those utilized by the Physical Fitness Course lecturers. The psychometric properties of these tests were estimated (i.e., the instrument reliability coefficient was 0.82 ). Prior and post measurements were taken. Means, standard deviations, and $(t)$ test was computed. The primary result revealed a clear improvement in the participants' physical fitness components level in the post-measurements.
\end{abstract}

\section{Keywords}

Physical Fitness, Circuit Training Method, College Students

\section{Introduction}

Workers in the sports field concerned about looking for the best ways and education method as well as training methods to reach with the trainee to the highest possible levels of physical and motor fitness. These methods became the foundations for building and promotion, since they were used for all forms of sports with their various types. Here, the coach should select the most appropriate method in training.

"Circuit Training" term emerged in the sports training arenas in late of 1950s, when it was first introduced by 
Morgan and Adamson. At that time, the basic objective of the circuit training was limited to being a training system seeking for increasing the students' physical fitness within the sports activities limits inside schools. Circuit training is a work style that depends on organizing its domains on the well-known training methods (i.e., continuous, interval, and recurring). Load rationing process within the circuit training methods was governed by the applicable ways in this field, in terms of intensity, volume, and intra-rest periods (Al-Abhar, 2001).

Circuit training is a number of exercises with specified objectives which takes into consideration its design, rationing, and load variation the principle of the individual differences among the players. This can be achieved either by time-specific exercises with constant rest periods, or by time exercises performed during the shortest possible time within an entire circuit of exercises (cycle), where the initial objective of the performance is achieving it within the shortest possible period (Reddy \& Jyoti, 2012).

When designing the circuit training units, changing the load through the stations should be taken into consideration in a manner compatible to the basic muscle groups. Circuit training is a fertile field for the development of the educational aspects. In this concern, self-dependence, work, and self-assessment are widely available in the circuit training. Circuit training has many educational advantages such as availing mutual respect opportunity among the individuals and respecting those with humble abilities and capabilities equally at the same level of respect to those of higher abilities (Reddy \& Jyoti, 2012).

The circuit training method is one of the ways that take into account the individual differences, the players' levels and abilities, and the possibility of gradually upgrading the load grade. Additionally, it provides a chance to focus on a specific physical fitness component which needs to be promoted; thereby it avails chances for self-assessment. In addition, it is a system that helps in saving time and effort. Many individuals can be trained at the same time, because achieving the performance in the shortest time possible is the initial objective of the performance (Oudat \& Ghassab, 2007).

Furthermore, this method is one of the ways of physical fitness training aiming to a general development which includes all the physical aspects, as well as the heart and blood vessels fitness (Scholich, 1990). Hamoudat (2008) indicates that the circuit training method represents a certain system and style in training based on the rules and laws derived from the analysis of the used training load. It is an organized method to perform the exercises with or without tools, where certain conditions are observed concerning selection of the exercises, recurrence, intensity, and intra-rest periods. They may be formed through the three basic training ways: continuous, interval, and recurring.

The role of the teacher or trainer in the circuit training method is different from that in other training methods. In this method, the teacher prepares the educational environment and follows up the students' progress in learning. He also directs the students' behavior during learning, and provides them with assistance, if necessary.

The sport training has a wide role in promoting the physical fitness components. The circuit training is considered as a vital part of the training program, particularly in warming-up section. This section is very essential in the training process. Not only it provides students with skills and develops many of their abilities and motor experiences, but also it provides them with necessary knowledge related to the health and scientific aspects of the body formation. This can be achieved by using the motor activities as well as group and individual games in the training lesson (Oudat \& Ghassab, 2007).

The researcher believes that the results of this study assist the workers in the sports domain to apply it in the various age stages, and utilize the learning time effectively and optimally. In addition, the current study contributes to developing the students' social skills through discussions, exchange of experiences, and providing them with the required feedback.

The literature review (Hamoudat, 2008; Oudat \& Ghassab, 2007; Al-Rashidi, 2006) reveals that there is a decline of the physical fitness components among the college students. The researcher, through his work within the education and training domains, finds a decline in the components of the physical fitness among students who are enrolled in the Faculty of Physical Fitness and Sports Science. The current study fills the gap in the professional literature. Therefore, the researcher applied a training program using the circuit training method to identify the improvement degree in the components of the physical fitness of the students. This was achieved by taking pre/post measurements of the tests that measured the physical fitness components.

\subsection{Objectives}

The primary objectives are the following: 
1) Identifying the effect of using the circuit training method on promoting the physical fitness components among the Hashemite University freshmen students who are enrolled in the Physical Fitness Course at the Faculty of Physical Education and Sports Sciences as related to gender.

2) Identifying the differences between the pre- and post-tests of the females and males.

\subsection{Hypotheses}

The hypotheses of the study are:

1) There are statistically significant differences in the pre- and post-test between the females and males at the significance level $(\alpha<0.05)$.

2) There are no statistically significant differences in the post-test between the females and males at the significance level $(\alpha<0.05)$.

\section{Methodology}

\subsection{Study Design}

The researcher utilized the experimental design because it is appropriate for the nature and the objectives of the study.

\subsection{Study Population}

The study population consisted of all male and female freshmen students who were registered in the records of the Physical Fitness Course which is offered by the Faculty of Physical Education and Sport Science at the Hashemite University in the first semester of the academic year 2013/2014.

\subsection{Sample}

To obtain the desired sample size $(n=30)$, an intentional sample method was utilized. The Faculty of Physical Education and Sport Science at the Hashemite University offered only one section of the Physical Fitness Course in the first semester of the academic year 2013/2014. This section consisted of 36 students. Six of them were excluded from the study due to not attending the class regularly and not dressing the sport uniform. Therefore, the desired sample size is 30 (i.e., 15 male and 15 female students).

The researcher performed the appropriate statistical analyses (i.e., means, standard deviations, and t-value) to make sure that the sample is characterized by parity in all the anthropometric variables (i.e., age, height, weight), and in the physical tests (i.e., Sitting from the prone position, Vertical Jump, Slope Prostration-Arms Bent, Long Jump with Stability, Zigzag Running, and Trunk Bending from Standing) (see Table 1).

The primary ethics were taken into consideration. Permission was obtained from the Faculty of Physical Education and Sport Science at the Hashemite University prior to proceeding with the study. The participants were given informed consent to participate in the study. The data was kept by the researcher in a secured location. The findings were accessible only to the researcher.

\subsection{Study Instrument}

The researcher determined the tests that measure the physical fitness components based on those utilized by the Physical Fitness Course lecturers. These tests were sitting from the Prone position, Vertical Jump, Slope Pros Tration-Arms Bent, Long Jump with Stability, Zigzag Running, and Trunk Bending from Standing. The psychometric properties of these tests were estimated (i.e., the instrument reliability coefficient was $(0.82)$. The training units were designed using the low intensity internal load; and they were applied at the rate of two units/week, over (8) weeks, which included (6) stations to train the students on.

\subsection{Statistical Analyses}

Data analyses were performed by using version 11.5 of the Statistical Package for Social Sciences (SPSS). Descriptive statistics (i.e., means and standard deviations) and ( $\mathrm{t}$ ) test was computed to achieve the objectives of the current study. 


\section{Results and Discussion}

With regard to the sample characteristics and the physical tests at the baseline data, Table 1 shows that all significance levels in the growth rates and physical tests is higher than 0.05 . This indicates that there are no statistically significant differences between the study sample at $(\alpha<0.05)$ level in the anthropometric variables (i.e., age, height, weight), and in the physical tests (i.e., Sitting from the prone position, Vertical Jump, Slope Prostration-Arms Bent, Long Jump with Stability, Zigzag Running, and Trunk Bending from Standing), which indicate the sample equivalence of the sample on these variables.

Regarding the results of the first hypothesis of this study "There are statistically significant differences at the significance level $(\alpha<0.05)$ between the pretest and posttest of the females and males", the researcher examined it by estimating the mean scores differences, the standard deviations; and $(\mathrm{t})$ value of the difference significance, which are presented in Table 2.

Table 2 confirms the hypothesis about the existence of statistically significant differences at the significance

Table 1. Study sample equivalence in the age, height, weight, and physical tests $(n=30)$.

\begin{tabular}{|c|c|c|c|c|c|c|}
\hline \multirow{2}{*}{ Growth Rates } & \multicolumn{2}{|c|}{ Females } & \multicolumn{2}{|c|}{ Males } & \multirow{2}{*}{$\mathrm{T}$} & \multirow{2}{*}{$P$ Value } \\
\hline & M & SD & M & SD & & \\
\hline Age & 17.58 & 0.22 & 17.60 & 0.21 & 0.24 & 0.715 \\
\hline Height & 160.36 & 1.41 & 160.26 & 1.56 & 0.32 & 0.543 \\
\hline Weight & 58.68 & 1.85 & 58.44 & 1.49 & 1.27 & 0.421 \\
\hline Sitting from the prone position & 2.42 & 1.10 & 2.41 & 1.20 & 2.07 & 0.421 \\
\hline Vertical Jump & 2.22 & 1.04 & 2.13 & 1.16 & 0.14 & 0.547 \\
\hline Slope prostration-arms bent & 2.32 & 1.72 & 2.18 & 1.55 & 0.79 & 0.785 \\
\hline Long jump with stability & 2.25 & 1.05 & 2.24 & 1.35 & 0.48 & 0.357 \\
\hline Zigzag running & 2.25 & 1.22 & 2.62 & 1.38 & 0.12 & 0.224 \\
\hline Trunk bending from standing & 2.44 & 1.61 & 2.11 & 1.17 & 0.22 & 0.141 \\
\hline
\end{tabular}

Table 2. Paired sample t-test for the differences in pretests-posttests of the males and females.

\begin{tabular}{|c|c|c|c|c|c|c|c|}
\hline \multirow{2}{*}{ Test } & \multirow{2}{*}{ Gender } & \multicolumn{2}{|c|}{ Pre Test } & \multicolumn{2}{|c|}{ Post Test } & \multirow{2}{*}{$\mathrm{T}$} & \multirow{2}{*}{$P$ Value } \\
\hline & & M & SD & $\mathrm{M}$ & $\mathrm{SD}$ & & \\
\hline \multirow{2}{*}{$\begin{array}{l}\text { Sit ting from the } \\
\text { prone position }\end{array}$} & Females & 2.42 & 1.10 & 3.75 & 0.25 & 10.81 & 0.014 \\
\hline & Males & 2.41 & 1.20 & 4.01 & 0.90 & 12.04 & 0.000 \\
\hline \multirow{2}{*}{ Vertical jump } & Females & 2.22 & 1.04 & 3.52 & 1.21 & 11.21 & 0.020 \\
\hline & Males & 2.13 & 1.16 & 3.65 & 0.20 & 13.32 & 0.001 \\
\hline \multirow{2}{*}{ Slope prostration-arms bent } & Females & 2.32 & 1.72 & 3.64 & 1.30 & 15.67 & 0.001 \\
\hline & Males & 2.18 & 1.55 & 3.77 & 1.14 & 12.03 & 0.000 \\
\hline \multirow{2}{*}{$\begin{array}{l}\text { Long jump with } \\
\text { stability }\end{array}$} & Females & 2.25 & 1.05 & 3.47 & 1.41 & 20.87 & 0.001 \\
\hline & Males & 2.24 & 1.35 & 3.70 & 1.12 & 22.34 & 0.001 \\
\hline \multirow{2}{*}{ Zigzag running } & Females & 2.25 & 1.22 & 3.20 & 1.26 & 15.97 & 0.005 \\
\hline & Males & 2.62 & 1.38 & 3.78 & 0.42 & 11.34 & 0.001 \\
\hline \multirow{2}{*}{$\begin{array}{l}\text { Trunk bending } \\
\text { from standing }\end{array}$} & Females & 2.44 & 1.61 & 4.56 & 1.17 & 18.23 & 0.000 \\
\hline & Males & 2.11 & 1.17 & 3.38 & 0.33 & 13.02 & 0.000 \\
\hline
\end{tabular}


level $(\alpha<0.05)$ in the test results between the pretest and posttest of the females and males. This result is consistent with the findings as reported in previous research by Arazi \& Asadi (2012), Thomas et al. (2009), and Al-Rashidi (2006), which indicated that using the circuit training method has its effectiveness in increasing and promoting physical fitness components.

With regard to the results of the second hypothesis of this study "There are no statistically significant differences at the significance level $(\alpha<0.05)$ between the pretest and posttest of the females and males", Table 3 presented the findings.

Table 3 shows the existence of non-statistically significant differences in the results of the posttests in all the tests, except for the test of trunk bending from standing, which was in favor of the females. The researcher believes that this result is due to the nature of female joint flexibility. Additionally, no significant differences exist between male and female participants in other tests (i.e., sitting from the prone position, vertical jump, slope prostration-arms bent, long jump with stability, and zigzag running). This finding might be explained as a result of attending both of them the same course at the same time and applying the exact instructions. This condition yields them to get the same level of the benefits (i.e., the same increase in their other physical fitness components) from participating in the Physical Fitness Course.

In other words, these findings indicate that using the circuit training method led to same noticeable improvement in the performance of all participants. These findings are in agreement with those of the studies of Alam et al. (2012), Taskin (2009), Jood Allah (2009), Hamoudat (2008), and Al-Wadayan (2001), which indicated that the circuit training method in the physical education lesson has an effective impact on the development and improvement of the physical fitness components, and creating a functional adaptation in their respiratory and circulatory systems.

\section{Conclusion}

The primary conclusion was drawn on the basis of the study findings. The study emphasizes that using recruit training method leads to promote the physical fitness components among the participants.

\section{Recommendations}

In the light of the results of this study, the researcher recommends that it is essential for the lecturers in the universities who teach physical fitness courses to invest the circuit training method in teaching and training. The researcher further advises them to the use of the methods and styles that fit the students and diversification in the provision of audio-visual aids in education.

\section{Limitations}

Due to the nature of the study design, the study has several limitations: a) the sample was limited to freshmen students at the Hashemite University who are enrolled in selected sections of physical fitness course; b) the findings are generalizable only to the target population and to the same setting; c) bias existed due to those students who were enrolled in other physical fitness sections and not had a chance to participate; d) the extraneous variables of environment (such as training and participating of the students in sports activities inside and outside

Table 3. Independent sample t-test between male and female in post test.

\begin{tabular}{|c|c|c|c|c|c|c|}
\hline \multirow{2}{*}{ Growth Rates } & \multicolumn{2}{|c|}{ Females } & \multicolumn{2}{|c|}{ Males } & \multirow[t]{2}{*}{$\mathrm{T}$} & \multirow{2}{*}{$\begin{array}{c}\text { Significance } \\
\text { Level }(\alpha)\end{array}$} \\
\hline & M & $\mathrm{SD}$ & M & $\mathrm{SD}$ & & \\
\hline Sitting from the prone position & 3.75 & 0.25 & 4.01 & 0.90 & 0.458 & 0.401 \\
\hline Vertical jump & 3.52 & 1.21 & 3.65 & 0.20 & 0.336 & 0.103 \\
\hline Slope prostration-arms bent & 3.64 & 1.30 & 3.77 & 1.14 & 1.448 & 0.203 \\
\hline Long jump with stability & 3.47 & 1.41 & 3.70 & 1.12 & 0.545 & 0.601 \\
\hline Zigzag running & 3.20 & 1.26 & 3.78 & 0.42 & 0.510 & 0.703 \\
\hline Trunk bending from standing & 4.56 & 1.17 & 3.38 & 0.33 & 8.86 & 0.000 \\
\hline
\end{tabular}


the university) cannot be completely controlled.

\section{References}

Al-Abhar, M. (2001). Teaching and School Sports Activities. Cairo: Faculty of Physical Education for Men, Holwan University.

Alam, S., \& Pahlavni, H., \& Mehdipour, A. (2012). The Effect of Plyometric Circuit Exercises on the Physical Preparation Indices of Elite Handball Player. Physical Education and Sport, 10, 89-98.

Al-Rashidi, N. (2006). Proposed Training Curriculum to Develop Certain Elements of the Physical Fitness and the Skillful Performance in the Ground Movements. Unpublished MA Thesis, Mosul: Faculty of Physical Education, University of Mosul.

Al-Wadayan, H. (2001). Effect of the Use of the Circuit Training Method by the High Intensity Interval Load Manner, for the Development of Certain Physical Attributes, on the Improvement of the Performance Time for $100 \mathrm{~m}$ Freestyle Swimming, Below (15) Years. Al-Yarmouk Research Journal, 3, 126-145.

Arazi, H., \& Asadi, A. (2012). Multiple Sets Resistance Training: Effects of Condensed versus Circuit Models on Muscular Strength, Endurance and Body Composition. Journal of Human Sport \& Exercise, 7, 733-740.

Hamoudat, M. (2008). Effect of the Circuit Training Using the Low Intensity Interval Training Method in the Development of Certain Physical Fitness Elements. Al-Rafidain Sports Science Journal, 14, 216-231.

Jood Allah, H. (2009). Effect of the Use of Two Methods in the Circuit Training on the Development of Certain Physical Attributes of the Beginners, Comparative Study. Unpublished MA Thesis, Al-Yarmouk: Al-Yarmouk University.

Oudat, M., \& Ghassab, I. (2007). Proposed Training Program Using the Circuit Training Method and its Effects on the Development of Certain Physical Attributes in the Physical Education Lesson. Scientific Journal for Physical Education Science, 3, 76-98.

Reddy, M., \& Jyoti (2012). Comparison of Circuit Training Methods on Performance Variables of Sc/St Non-Sc/St Boys. International Journal of Multidisciplinary Research, 2, 221.

Scholich, M. (1990). Circuit Training for All Sports: Methodology of Effective Fitness Training. Toronto: Sport Books Publisher.

Taskin, H. (2009). Effects of Circuit Training on the Sprint-Agility and Anaerobic Endurance. Journal of Strength and Conditioning Research, 23, 1803-1810. http://dx.doi.org/10.1519/JSC.0b013e3181b3dfc0

Thomas, K., French, D., \& Hayes, P. (2009). The Effect of Two Polymeric Training Techniques on Muscular Power and Agility in Youth Soccer Players. Journal of Strength and Conditioning Research, 23, 332-335.

http://dx.doi.org/10.1519/JSC.0b013e318183a01a 